\title{
MANAJEMEN SARANA PRASARANA DI DAY CARE BABY'S HOME SALATIGA
}

\author{
Desi Kusumawati \\ desi.kusumawati@staff.uksw.edu \\ Program Studi PAUD, Fakultas Keguruan dan Ilmu Pendidikan - UKSW
}

\author{
ABSTRACT \\ The Infrastructures Management In Baby's Home \\ Day Care Salatiga
}

Day Care is one form of early childhood education in non formal education program that organize nurturing and social welfare of children from birth up to the age of 6 years. This study aimed to identify the suitability of existing infrastructure in Baby's Home day care with the ACT of Minister of Education and Culture No. 137 of 2014 Article 32 Paragraph 3; and to provide an overview why the planning, maintenance and inventory in Baby's Home day care were not optimal. This study was qualitative research. The subject was Baby's Home day care Salatiga. Technique of collecting data using interviews, observation and documents. Data were analyzed using Miles and Huberman Model. Data validation using triangulation technique of data. Facilities and infrastructure in Baby's Home day care which conform with ACT of Minister of Education and Culture No. 137 of 2014 Article 32 Paragraph 3 of were the area of land, space of activities inside and outside, hand washing facilities, showers and latrines, and access to health facilities. While things were not conform included the bedroom, dining room, and covered trash. The cause of the planning, maintenance and inventory of facilities and infrastructure have not optimally done because the plan was not carried out continuously, the lack of personnel to assist in the maintenance, and did not have the administrative staff specifically for inventory. Advice can be given to Baby's Home day care is to conduct procurement planning infrastructure on sleeping room, dining room and trash. In addition, the maintenance to existing infrastructure must be made as well as the inventory of infrastructure in order to facilitate the planning purchasing.

Keywords: Management, Facilities, Day Care, Early Childhood

\section{PENDAHULUAN}

Direktur Jenderal Pendidikan Anak Usia Dini dan Pendidikan Masyarakat, Harris Iskandar (2016) mengungkapkan, peningkatan kualitas PAUD sudah menjadi komitmen dunia. Keikutsertaan anak-anak pada program Pendidikan Anak Usia Dini (PAUD) di Indonesia meningkat pesat di tingkat Asia dan dunia., yakni pada tahun 2015 mencapai 70,1 persen. Kondisi tersebut menggambarkan bahwa jumlah lembaga PAUD yang ada yaitu Taman Kanak-Kanak (TK), Kelompok Bermain (KB), Day Care dan lembaga PAUD Sejenis Lainnya sudah semakin banyak. Day Care merupakan salah satu bentuk PAUD pada jalur pendidikan non formal yang menyelenggarakan program pendidikan sekaligus pengasuhan dan kesejahteraan sosial terhadap anak sejak lahir sampai dengan usia 6 tahun (Direktorat Pembinaan PAUD Kementerian Pendidikan Nasional, 2011).

Day Care menurut Direktorat Pembinaan PAUD Kementerian Pendidikan dan Kebudayaan (2015) terbagi menjadi dua jenis yaitu berdasarkan waktu layanan dan tempat penyelenggaraan day 
care yang berdasarkan waktu layanan terdiri dari sehari penuh (full day), setengah hari (half day), dan temporer. Sedangkan day care yang berdasarkan tempat penyelenggaraan terdiri dari day care perumahan, day care pasar, day care pusat pertokoan, day care rumah sakit, day care perkebunan, day care perkantoran, day care pantai, day care pabrik, day care mall. Day Care Baby's Home Salatiga termasuk dalam jenis day care full day, karena day care ini diselenggarakan satu hari penuh dari jam 07.00 sampai jam 17.00 untuk melayani peserta didik yang dititipkan baik yang dititipkan sewaktu-waktu maupun dititipkan rutin/setiap hari.

Setiap satuan pendidikan formal dan non formal menyediakan sarana dan prasarana yang memenuhi keperluan pendidikan sesuai dengan pertumbuhan dan perkembangan potensi fisik, kecerdasan intelektual, social, emosional dan kejiwaan peserta didik (UU No. 20 Tahun 2003 Pasal 45 Ayat 1). Day care perlu menyediakan sarana dan prasarana. Sarana dan prasarana merupakan perlengkapan dalam penyelenggaraan dan pengelolaan kegiatan pendidikan, pengasuhan, dan perlindungan anak usia dini (Permendikbud 137 Tahun 2014 Pasal 31).

Sarana dan prasarana yang ada di sebuah day care perlu dikelola dengan baik. Manajemen sarana prasarana bertugas mengatur dan menjaga sarana dan prasarana pendidikan agar dapat memberikan kontribusi secara optimal dan berarti pada jalannya proses pendidikan. Kegiatan pengelolaan ini meliputi kegiatan perencanaan, pengadaan, pengawasan, penyimpanan, inventarisasi, penghapusan serta penataan. (Slameto, 2009).

Baby's Home sebagai salah satu day care yang ada di Salatiga memiliki sarana dan prasarana sebagai penunjang keberlangsungan day care. Sarana dan prasarana yang ada di day care Baby's Home berdasarkan hasil wawancara diperoleh informasi bahwa pengadaannya tidak melihat pedoman dari Permendikbud 137 Tahun 2014 Pasal 32 Ayat 3, sehingga sesuai atau tidaknya pemilik tidak mengetahuinya. Perencanaan, pengadaan, pendistribusian, penggunaan, pemeliharaan, inventaris, penghapusan merupakan bagian dari manajemen sarana prasarana yang perlu didayagunakan secara efektif dan efisien (Bafadal, 2010). Hasil wawancara di day care Baby's Home diperoleh informasi bahwa pembelian barang kadang-kadang dibuat perencanaan dan untuk pemeliharaan dan inventaris pelaksanannya belum maksimal.

Penelitian ini bertujuan: untuk mengidentifikasi kesesuaian sarana prasarana yang ada di day care Baby's Home dengan Permendikbud 137 Tahun 2014 Pasal 32 Ayat 3; dan untuk memberikan gambaran penyebab belum maksimalnya perencanaan, pemeliharaan dan inventaris yang ada di day care Baby's Home. Manfaat penelitian ini adalah sebagai bahan pertimbangan bagi pemilik day care Baby's Home dalam mengelola sarana dan prasarana yang ada.

\section{KAJIAN PUSTAKA}

\section{Day Care}

Day Care/ Taman Penitipan Anak (TPA) mampu menjawab kebingungan pasangan suami istri yang kedua-duanya bekerja. Manfaat yang akan didapatkan oleh pasangan suami istri yang menitipkan anaknya di day care antara lain anak akan belajar bersosialisasi dengan teman-temannya, anak akan mendapatkan pengetahuan, wawasan serta keterampilan yang bisa meningkatkan kemampuan anak. Salah satu indikator keberhasilan day care adalah adanya sarana dan prasarana yang memadai.

Tujuan diselenggarakannya day care menurut Direktorat Pembinaan PAUD (2011) adalah memberikan layanan kepada anak usia 0-6 tahun yang terpaksa ditinggal orang tua karena pekerjaannya atau halangan lainnya, memberikan layanan yang terkait dengan pemenuhan hak-hak anak untuk tumbuh dan berkembang, mendapatkan perlindungan dan kasih sayang, serta hak untuk berpartisipasi dalam lingkungan sosialnya. 


\section{Manajemen Sarana Prasarana di Day Care}

Fasilitas atau sarana dapat diartikan segala sesuatu yang dapat memudahkan dan melancarkan pelaksanaan usaha ini dapat berupa benda maupun uang. Fasilitas atau sarana dapat dibedakan menjadi dua jenis yaitu: fasilitas fisik dan fasilitas uang. Fasilitas fisik yakni segala sesuatu yang berupa benda atau fisik yang dapat dibendakan, yang mempunyai peranan untuk memudahkan dan melancarkan suatu usaha. Sedangkan fasilitas uang yakni segala sesuatu yang bersifat mempermudah suatu kegiatan sebagai akibat bekerjanya nilai uang (Arikunto \& Yuliana, 2012).

Bagian yang erat kaitannya dengan sarana pendidikan adalah prasarana pendidikan. Prasarana pendidikan menurut Susilo (2008) adalah fasilitas yang secara tidak langsung menunjang jalannya proses pendidikan atau pengajaran. Sedangkan Arikunto (1987) mengatakan prasarana pendidikan, yaitu segala sesuatu yang tidak berhubungan secara langsung dengan proses pembelajaran antara lain bangunan sekolah, ruang kelas, ruang perpustakaan, lapangan, kebun sekolah, dan lain-lain. Prasarana pendidikan dapat diklasifikasikan menjadi dua macam menurut Prihatin (2011) yaitu: 1) Prasarana pendidikan yang secara langsung digunakan untuk proses belajar mengajar, seperti ruang teori, ruang perpustakaan, ruang praktek keterampilan, ruang laboratorium; dan 2) Prasarana pendidikan yang keberadaannya tidak digunakan untuk proses belajar mengajar, seperti ruang kantor, kantor sekolah, tanah dan jalan menuju sekolah, kamar kecil, ruang usaha, kesehatan sekolah, ruang guru, ruang kepala sekolah dan tempat parkir kendaraan

Manajemen sarana sering disebut dengan manajemen materiil, yaitu segenap proses penataan yang bersangkut-paut dengan pengadaan. Sarana pendidikan merupakan sarana penunjang bagi proses belajar mengajar. Manajemen sarana prasarana menurut Bafadal (2010) adalah suatu proses kerjasama pendayagunaan semua perlengkapan pendidikan secara efektif dan efisien meliputi perencanaan, pengadaan, pendistribusian, penggunaan, pemeliharaan, inventaris, penghapusan. Sedangkan Hartani (2011), memberikan definisi manajemen sarana dan prasarana pendidikan sebagai suatu aktivitas menyeluruh yang dimulai dari perencanaan, pengadaan, penggunaan, pemeliharaan, dan penghapusbukuan berbagai properti pendidikan yang dimiliki oleh suatu institusi pendidikan.

Suryosubroto (2004) mengatakan manajemen sarana dan prasarana dibagi menjadi lima hal, yaitu: (a) penentuan kebutuhan; (b) proses pengadaan; (c) pemakaian; (d) pengurusan dan pencatatan; dan (e) pertanggungjawaban. Penentuan kebutuhan sarana dan prasarana merupakan bagian dari perencanaan. Untuk merencanakan kebutuhan, Arikunto (2012) mengatakan perlu melalui tahap-tahap tertentu yaitu: 1) mengadakan analisis kebutuhan, dari analisis ini dapat didaftar alat-alat/media apa yang dibutuhkan oleh guru; 2) apabila kebutuhan yang diajukan oleh guru ternyata melampaui kemampuan daya beli atau daya pembuatan, maka harus diadakan seleksi menurut skala prioritas terhadap alat-alat yang mendesak pengadaannya. Kebutuhan lain dapat dipenuhi pada kesempatan lain; 3) mengadakan inventarisasi terhadap alat/media yang telah ada; 4) mengadakan seleksi terhadap alat/media yang dapat dimanfaatkan baik dengan reparasi atau modifikasi maupun tidak; 5) mencari dana (bila belum ada); 6) menunjuk seseorang untuk melaksanakan pengadaan alat.

Pengaturan dan penggunaan sarana merupakan dua kegiatan yang tidak dapat dipisahkan karena dilaksanakan silih berganti. Kegiatan pertama yang dilakukan adalah inventaris dan pencatatan ke dalam buku daftar inventaris. Perlu juga menyediakan tempat penyimpanan untuk barang-barang, yang mana kadangkala hal ini sering dilupakan sehingga ketika barang datang kebingungan untuk menyimpannya.

Barang-barang yang ada di day care harus dijaga benar keberadaannya agar tidak lekas rusak. Beberapa jenis barang mungkin begitu rusak satu kali sudah tidak dapat diperbaiki lagi, tetapi ada beberapa jenis barang yang masih bisa direparasi. Mungkin juga barang tersebut dapat digunakan akan tetapi satu atau dua kali kemudian rusak dan harus diperbaiki lagi. Dalam penghitungan biaya, kerugian yang ditimbulkan karena kerusakan harus diperhitungkan sebagaimana harga. Bila kerugian memperbaiki barang jauh lebih besar maka barang tersebut sebaiknya disingkirkan. 
Urusan penyingkiran barang dapat diartikan sama dengan penghapusan barang. Fungsinya adalah mencegah kerugian yang jauh lebih besar, meringankan beban kerja inventarisasi karena banyaknya barang-barang yang tinggal menyusut, membebaskan barang-barang dari tanggung jawab satuan organisasi atau lembaga yang mengurusnya. Penghapusan atau penyingkiran barang dapat melalui tahap-tahap seperti yang dikemukakan oleh Arikunto (2012) yaitu: (1) pemilihan barang yang dilakukan tiap tahun bersamaan dengan waktu memperkirakan kebutuhan; (2) memperhitungkan factor-faktor penyingkiran dan penghapusan ditinjau dari segi nilai uang; (3) membuat perencanaan; (4) membuat surat pemberitahuan kepada yang akan diadakan penyingkiran dengan menyebutkan barang-barang yang akan disingkirkan; (5) melaksanakan penyingkiran dengan cara: mengadakan lelang, menghibahkan kepada Badan orang lain, membakar, penyingkiran disaksikan oleh atasan, membuat berita acara tentang pelaksanaan penyingkiran.

Prinsip pengadaan sarana prasarana menurut Permendikbud 137 Tahun 2014 Pasal 31 Ayat 3 yaitu: a) aman, bersih, sehat, nyaman, dan indah; 2) sesuai dengan tingkat perkembangan anak; 3) memanfaatkan potensi dan sumber daya yang ada di lingkungan sekitar, dan benda lainnya yang layak pakai serta tidak membahayakan kesehatan anak. Persyaratan sarana prasarana day care menurut Permendikbud 137 Tahun 2014 Pasal 32 Ayat 3 meliputi: a) Memiliki jumlah ruang dan luas lahan disesuaikan dengan jumlah anak, luas minimal $3 \mathrm{~m}^{2}$ per anak; b) Memiliki ruangan untuk melakukan aktivitas anak di dalam dan luar; c) Memiliki fasilitas cuci tangan dengan air bersih; d) Memiliki kamar mandi/ jamban dengan air bersih yang cukup, aman dan sehat bagi anak serta mudah bagi melakukan pengawasan; e) Memiliki fasilitas permainan di dalam dan di luar ruangan yang aman dan sehat; f) Memiliki tempat sampah yang tertutup dan tidak tercemar; g) Memiliki akses dengan fasilitas layanan kesehatan seperti rumah sakit ataupun puskesmas; dan h) PAUD kelompok usia lahir 2 tahun, memiliki ruang pemberian ASI yang nyaman dan sehat.

\section{METODE}

Jenis penelitian ini adalah penelitian kualitatif. Subyek dalam penelitian ini adalah Day Care Baby's Home Salatiga. Teknik pengumpulan data menggunakan wawancara, observasi dan dokumen. Teknik analisis data menggunakan analisis model interaktif Model Miles dan Huberman (dalam Sugiyono, 2012). Pengujian kredibilitas menggunakan triangulasi teknik pengumpulan data (Sugiyono, 2012). Aktivitas dalam analisis data yaitu reduksi data, penyajian data, penarikan kesimpulan dan verifikasi. Adapun rincian bentuk analisis tersebut dapat diuraikan sebagai berikut:

1. Reduksi Data

Data-data yang diperoleh dari lapangan dicatat dalam bentuk deskriptif naratif, yaitu uraian data yang diperoleh di day care Baby's Home apa adanya tanpa ada komentar peneliti tentang rangkaian manajemen sarana dan prasarana dalam bentuk catatan-catatan kecil dan transkrip wawancara.

\section{Penyajian Data}

Pada tahap ini disajikan data hasil temuan di lapangan dalam bentuk naratif, yaitu uraian tertulis tentang proses dan aktivitas manajemen sarana dan prasarana di day care Baby's Home

3. Penarikan simpulan / verifikasi

Penarikan kesimpulan dan verifikasi merupakan upaya mencari makna dari komponenkomponen data yang disajikan dengan mencermati pola-pola, keteraturan, penjelasan konfigurasi dan hubungan sebab akibat. Dalam melakukan penarikan kesimpulan dan verifikasi tentang proses dan aktifitas manajemen sarana dan prasarana di day care Baby's Home, selalu dilakukan peninjauan terhadap penyajian data dan catatan di lapangan melalui triangulasi teknik

\section{HASIL DAN PEMBAHASAN}


Penelitian ini dilaksanakan di day care Baby's Home Salatiga. Jumlah anak asuhnya ada tujuh anak. Berdasarkan dokumen dan observasi diperoleh data seperti yang terdapat dalam tabel 1.

Tabel 1. Kondisi Ruangan

\begin{tabular}{|c|c|c|c|c|c|c|}
\hline \multirow[t]{2}{*}{ No } & \multirow[t]{2}{*}{ Jenis Ruang } & \multirow{2}{*}{$\begin{array}{l}\text { Tidak } \\
\text { Ada }\end{array}$} & \multirow[t]{2}{*}{ Ada } & \multicolumn{3}{|c|}{ Kondisi } \\
\hline & & & & Baik & Rusak Ringan & Rusak Berat \\
\hline 1. & Ruang Tidur & & $\sqrt{ }$ & $\sqrt{ }$ & & \\
\hline 2. & Ruang Makan & & $\sqrt{ }$ & $\sqrt{ }$ & & \\
\hline 3. & Ruang Tamu & & $\sqrt{ }$ & $\sqrt{ }$ & & \\
\hline 4. & $\begin{array}{l}\text { Ruang } \\
\text { Administrasi }\end{array}$ & & $\sqrt{ }$ & $\sqrt{ }$ & & \\
\hline 5. & Kamar Mandi & & $\sqrt{ }$ & $\sqrt{ }$ & & \\
\hline 6. & $\begin{array}{l}\text { Ruang Aktivitas } \\
\text { Indoor }\end{array}$ & & $\sqrt{ }$ & $\sqrt{ }$ & & \\
\hline 7. & $\begin{array}{l}\text { Ruang Aktivitas } \\
\text { Outdoor }\end{array}$ & & $\sqrt{ }$ & $\sqrt{ }$ & & \\
\hline 8. & Ruang Laktasi & $\sqrt{ }$ & & $\sqrt{ }$ & & \\
\hline 9. & Ruang Dapur & & $\sqrt{ }$ & $\sqrt{ }$ & & \\
\hline
\end{tabular}

Seluruh ruangan seperti yang terdapat dalam tabel 1 tersedia di day care Baby's Home kecuali ruang laktasi dan berada dalam kondisi baik. Data wawancara dengan pengasuh diperoleh informasi bahwa "ketidaksediaannya ruang laktasi dikarenakan usia minimal anak asuh yang bisa dititipkan di day care Baby's Home ialah dua tahun. Pengasuh mengatakan biasanya usia dua tahun itu anak sudah tidak lagi minum ASI sehingga ruang laktasi tidak disediakan”. Pernyataan pengasuh sinkron dengan dokumen berupa data usia anak asuh yang ada di day care Baby's Home.

Perencanaan dan analisis kebutuhan sarana dan prasarana di day care Baby's Home dilakukan kadang-kadang (tidak ditentukan waktunya). Informasi tersebut diperoleh dari wawancara dengan pengasuh bahwa "kadang-kadnag pengasuh bersama pengelola mengobservasi sarana dan prasarana apa yang perlu dibeli”. Pengelolaan sarana dan prasarana dilakukan langsung oleh pemilik day care Baby's Home Salatiga. Pelaksanaan analisis kebutuhan melibatkan pengasuh. Hasil wawancara dengan pengelola didapatkan informasi bahwa pelibatan pengasuh itu sangat penting buat saya, karena pengasuh yang bisa melihat perkembangan anak. Pernyataan tersebut diperkuat oleh hasil wawancara dengan pengasuh "sarana yang memadai membantu perkembangan anak, sehingga pengasuh membutuhkan sarana untuk menstimulasi perkembangan anak".

Hasil dari analisis kebutuhan yang dilakukan oleh pemilik day care Baby's Home dan pengasuh sangatlah beragam dan jumlahnya cukup banyak. Namun tidak semua kebutuhan bisa dipenuhi karena melihat anggaran yang dimiliki day care Baby's Home tidak hanya digunakan untuk pengadaan sarana saja melainkan untuk keseluruhan kegiatan di day care Baby's Home. Keterbatasan anggaran dan besarnya jumlah kebutuhan terkadang tidak selalu sebanding sehingga perlu adanya penentuan skala prioritas dalam memilih kebutuhan mana saja yang akan diadakan oleh day care Baby's Home. Skala prioritas ini ditentukan oleh pengelola atau pemilik. Hasil wawancara dengan pengasuh memberikan gambaran bahwa kebutuhan utama untuk tahun ini adalah bangunan baru untuk day care Baby's Home, mengingat bangunan yang saat ini ditempati akan digunakan oleh pemilik sebagai tempat pembuatan es lilin dan warung makan.

Proses pengadaan sarana dan prasarana dilakukan langsung oleh pengelola day care Baby's Home. Proses pengadaan sarana sebagian besar dilakukan dengan cara membeli. Pembelian tersebut 
diambil dari dana yang dimiliki oleh day care Baby's Home yang bersumber dari biaya setiap anak asuh yang dititipkan (orang tua). Hal tersebut senada dengan hasil wawancara yang dilakukan oleh pengelola bahwa, "Dana untuk pengadaan sarana diperoleh dari orang tua anak asuh".

Kesesuaian persyaratan sarana dan prasarana yang ada di day care Baby's Home Salatiga menurut Permendikbud 137 Tahun 2014 Pasal 32 Ayat 3 dapat dilihat dalam tabel 2.

Tabel 2. Persyaratan Sarana dan Prasarana

\begin{tabular}{|c|c|c|c|}
\hline No. & Persyaratan Sarana dan Prasarana & Sesuai & Tidak Sesuai \\
\hline 1. & $\begin{array}{l}\text { Memiliki jumlah ruang dan luas lahan } \\
\text { disesuaikan dengan jumlah anak, luas } \\
\text { minimal } 3 \mathrm{~m} 2 \text { per anak }\end{array}$ & $\sqrt{ }$ & \\
\hline 2. & $\begin{array}{l}\text { Memiliki ruangan untuk melakukan } \\
\text { aktivitas anak di dalam dan luar }\end{array}$ & $\sqrt{ }$ & \\
\hline 3. & $\begin{array}{l}\text { Memiliki fasilitas cuci tangan dengan air } \\
\text { bersih }\end{array}$ & $\sqrt{ }$ & \\
\hline 4. & $\begin{array}{l}\text { Memiliki kamar mandi dengan air bersih } \\
\text { yang cukup, aman dan sehat bagi anak } \\
\text { serta mudah melakukan pengawasannya }\end{array}$ & $\sqrt{ }$ & \\
\hline 5 . & $\begin{array}{l}\text { Memiliki jamban dengan air bersih yang } \\
\text { cukup, aman dan sehat bagi anak serta } \\
\text { mudah melakukan pengawasannya }\end{array}$ & $\sqrt{ }$ & \\
\hline 6. & $\begin{array}{l}\text { Memiliki fasilitas ruang untuk tidur yang } \\
\text { aman dan sehat }\end{array}$ & & $\sqrt{ }$ \\
\hline 7. & $\begin{array}{l}\text { Memiliki fasilitas ruang untuk makan yang } \\
\text { aman dan sehat }\end{array}$ & & $\sqrt{ }$ \\
\hline 8. & $\begin{array}{l}\text { Memiliki tempat sampah yang tertutup dan } \\
\text { tidak tercemar }\end{array}$ & & $\sqrt{ }$ \\
\hline 9. & $\begin{array}{l}\text { Memiliki akses dengan fasilitas layanan } \\
\text { kesehatan seperti rumah sakit ataupun } \\
\text { puskesmas }\end{array}$ & $\sqrt{ }$ & \\
\hline 10. & $\begin{array}{l}\text { Memiliki ruang pemberian ASI yang } \\
\text { nyaman dan sehat }\end{array}$ & & $\sqrt{ }$ \\
\hline
\end{tabular}

Tabel 2 memberikan gambaran bahwa 6 dari 10 standar persyaratan sarana dan prasarana yang ada di day care Baby's Home sudah sesuai dengan Permendikbud 137 Tahun 2014 Pasal 32 Ayat 3. Data tersebut sinkron dengan pernyataan dari pengasuh day care Baby's Home yang mengatakan "Jumlah anak yang dititipkan di day care Baby's Home sebanyak tujuh anak, sehingga jika dihitung maka luas lahan yang dibutuhkan seharusnya adalah 7 anak x $3 \mathrm{~m}^{2}=21 \mathrm{~m}^{2}$ sedangkan luas lahan day care Baby's Home kira-kira 150 m².

Standar persyaratan sarana dan prasarana yang tidak sesuai dengan Permendikbud 137 Tahun 2014 Pasal 32 Ayat 3 adalah ruang untuk makan yang aman dan sehat, tempat sampah yang tertutup dan tidak tercemar, dan ruang pemberian ASI yang nyaman dan sehat. Kondisi itu senada dengan hasil wawancara dengan pengasuh yang mengatakan "Ada ruang makan tetapi meja dan kursinya terlalu tinggi hanya cocok untuk orang dewasa, sehingga ruang makan yang berdampingan dengan dapur tidak digunakan. Kami menggunakan ruang bermain sebagai ruang makan." Pengasuh mengatakan dalam wawancaranya "Tempat sampah yang ada hanya menggunakan kantong plastik hitam. Jenis sampah pun tidak dibedakan antara sampah organik dan an organic". 
Fasilitas ruang untuk tidur yang aman dan sehat belum sesuai dengan Permendikbud 137 Tahun 2014 Pasal 32 Ayat 3, karena hanya memiliki satu ruang tidur yang digunakan untuk semua anak. Keadaan itu senada dengan hasil wawancara dengan pengasuh yang mengatakan "Karakteristik usia yang ada di day care Baby's Home bervariasi mulai dari usia 2 tahun hingga usia 6 tahun, sehingga bila ruang tidurnya tidak dipisah maka keamanan anak saat tidur tidak terjamin". Hasil wawancara tersebut diperkuat dengan hasil observasi yang menunjukkan ada anak yang usia 2 tahun sedang tidur lalu anak yang usia 4 tahun melakukan aktivitas melompat-lompat di kasur.

Inventarisasi dilakukan untuk mencatat seluruh sarana dan prasarana yang dimiliki oleh sekolah sebagai data yang dapat digunakan untuk melihat sarana dan prasarana apa saja yang telah dimiliki oleh day care Baby's Home. Pelaksanaan inventarisasi dilakukan setelah proses pengadaan usai dan sebelum disalurkan ke sekolah untuk digunakan. Hal tersebut sesuai dengan pernyataan pengasuh yang menyatakan bahwa, "Setelah barang yang dibeli itu datang nanti pengasuh akan mencatatnya di dalam buku inventaris yang berisikan nama barang, sumber pengadaan, jumlah barang, bahan barang, dan tahun pembeliannya". Pernyataan tersebut diperkuat dengan dokumen sekolah yang menyebutkan bahwa, "penyaluran barang setelah diinventaris kedalam daftar inventaris barang".

Penyebab belum maksimalnya pelaksanaan inventaris adalah kurangnya sumber daya manusia. Pernyataan itu diperkuat oleh pemilik day care Baby's Home dalam wawancaranya yang mengatakan bahwa "Penambahan tenaga untuk mengurusi inventaris membutuhkan tambahan biaya lagi”.

Hasil penelitian menunjukan bahwa pemeliharaan sarana dan prasarana di day care Baby's Home dilakukan oleh seluruh warga day care Baby's Home. Pernyataan tersebut diperkuat dengan hasil wawancara dengan pengasuh yang mengatakan "anak-anak asuh diberi tanggung jawab untuk merawat dan memelihara barang-barang yang ada di sini tetapi tidak ada orang yang secara khusus mengurus ini". Berbeda dengan pernyataan pengasuh dalam wawancaranya, hasil observasi menunjukkan masih banyak barang-barang di day care Baby's Home yang kondisinya kurang terawatt. Penyebab belum maksimalnya pemeliharaan sarana dan prasarana adalah kurangnya sumber daya manusia. Hal tersebut sesuai dengan pernyataan pengelola dalam wawancaranya yang mengatakan bahwa penambahan tenaga untuk mengurus pemeliharaan membutuhkan biaya tambahan.

Penghapusan atau penyingkiran merupakan proses akhir dari kegiatan manajemen sarana dan prasarana di day care Baby's Home. Day care Baby's Home telah melakukan penghapusan atau penyingkiran barang yang tidak digunakan dengan cara menghibahkannya pada orang yang membutuhkan. Pernyataan ini seirama dengan pernyataan pengelola dalam wawancaranya yang mengatakan "Alat Peraga Edukatif (APE) yang sudah tidak terpakai di tempat kami dihibahkan kepada orang lain". Penghapusan ini dilakukan karena barang tersebut sudah tidak terpakai lagi.

Husain (2014) dalam penelitiannya tentang "Peran Pengelola TK Dalam Memfasilitasi Proses pembelajaran di TK Melati Indah Desa Loheluma KecamatanTilongkabila Kabupaten Bone Bolango" menunjukkan hasil bahwa masih ada sebagian fasilitas yang kurang memadai yang tidak dapat dipakai oleh anak didik sepenuhnya. Hasil penelitian Husain (2014) senada dengan hasil penelitian ini yaitu sama-sama masih ada sebagian fasilitas yang kurang memadai. Sedangkan Kartikasari (2014) dalam penelitiannya yang berjudul "Manajemen Sarana dan Prasarana Pembelajaran Di SD Tumbuh 1 Yogyakarta" menunjukkan hasil bahwa manajemen sarana dan prasarana pembelajaran di SD Tumbuh 1 Yogyakarta sudah cukup baik. Penelitian Kartikasari senada dengan hasil penelitian ini dimana dari 10 standar persyaratan hanya 6 yang memenuhi standar persyaratan sarana dan prasarana menurut Permendikbud 137 Tahun 2014 Pasal 32 Ayat 3.

Darmastuti dan Karwanto (2014) dalam penelitiannya yang berjudul "Manajemen Sarana dan Prasarana dalam Upaya Peningkatan Kualitas Pembelajaran Pada Jurusan Teknik Komputer dan Informatika di SMK Negeri 2 Surabaya menunjukkan hasil bahwa (1) pengadaan dan perencanaan 
sarana dan prasarana dilakukan dengan tujuan agar mengetahui semua kebutuhan sarana dan prasarana sekoah, direncanakan sejak awal tahun dengan melihat hasil evaluasi pada tahun sebelumnya (2) pendistribusian sarana dan prasarana dilakukan dengan cara menyeleksi sesuai kebutuhan, selanjutnya barang yang dibeli kemudian disalurkan kepada tiap program jurusan dan kelas. (3) penggunaan dan pemeliharaan sarana dan prasarana disesuaikan dengan kebutuhan guru dan siswa, ada tata tertib yang harus dipatuhi, diserahkan pada masing-masing program jurusan dan kelas. (4) ada staf sendiri yang diberi tugas untuk pencatatan barang yang telah diadakan. (5) penghapusan sarana dan prasarana terlebih dahulu membuat berita acara kepada kepala sekolah, dilakukan karena sarana dan prasarana tersebut sudah rusak. Hasil penelitian Darmastuti dan Karwanto (2014) berbeda dengan hasil penelitian ini. Perbedaannya yaitu perencanaan di day care Baby's Home tidak direncanakan sejak awal tahun, tidak ada staf sendiri yang diberi tugas untuk pencatatan barang yang telah diadakan, penghapuasan sarana prasarana tidak membuat berita acara terlebih dahulu.

\section{SIMPULAN}

Sarana dan prasarana yang ada di day care Baby's Home 6 dari 10 standar persyaratan sarana prasarana sudah sesuai dengan Permendikbud 137 Tahun 2014 Pasal 32 Ayat 3 yaitu luas lahan, ruang kegiatan di dalam dan luar, fasilitas cuci tangan, kamar mandi dan jamban, akses dengan fasilitas kesehatan. Sedangkan yang belum sesuai dengan standar persyaratan sarana prasarana menurut Permendikbud 137 Tahun 2014 Pasal 32 Ayat 3 adalah ruang tidur, ruang makan, tempat sampah tertutup. Penyebab perencanaan, pemeliharaan dan inventaris sarana dan prasarana belum dilakukan secara maksimal adalah perencanaan tidak dilakukan secara kontinyu, kurangnya tenaga untuk membantu melakukan pemeliharaan, tidak memiliki tenaga administrasi secara khusus untuk menginventaris barang. Hal ini dikarenakan keterbatasan dana.

Saran yang dapat diberikan kepada day care Baby's Home adalah agar melakukan perencanaan pengadaan sarana prasarana ruang tidur, ruang makan dan tempat sampah. Selain itu, perlu diusahakan pemeliharaan terhadap sarana prasarana yang telah ada agar terawat serta inventaris sarana prasarana pun perlu dilakukan agar memudahkan dalam melakukan perencanaan pembelian barang.

\section{DAFTAR PUSTAKA}

Anon. 2016. Tertinggi di Asia, APK PAUD Indonesia Tembus 70,1\%. Retrieved from http://news.prokal.co/read/news/1109-tertinggi-di-asia-apk-paud-indonesia-tembus-701persen.html.

Arikunto, Suharsimi. 1987. Pengelolaan materiil. Jakarta: Rineka Cipta

Arikunto, Suharsimi.,Yuliana, Lia. 2012. Manajemen Pendidikan. Yogyakarta: Fakultas Ilmu Pendidikan Universitas Negeri Yogyakarta

Bafadal, Ibrahim. 2008. Manajemen Perlengkapan Sekolah: Teori dan Aplikasinya. Cetakan Ketiga. Jakarta: PT Bumi Aksara

Darmastuti dan Karwanto. 2014. Manajemen Sarana dan Prasarana dalam Upaya Peningkatan Kualitas Pembelajaran Pada Jurusan Teknik Komputer dan Informatika di SMK Negeri 2 Surabaya. Jurnal Inspirasi Manajemen Pendidikan, 3 (3): 20-35.

Husain, Lian. 2014. Peran Pengelola TK Dalam Memfasilitasi Proses pembelajaran di TK Melati Indah Desa Loheluma Kecamatan Tilongkabila Kabupaten Bone Bolango. Skripsi. Universitas Negeri Gorontalo. 
Scholaria, Vol. 7 No 1, Januari 2017: 17 - 25

Kartikasari, Oktina Dwi. 2015. Manajemen Sarana dan Prasarana Pembelajaran Di SD Tumbuh 1 Yogyakarta. Skripsi. Universitas Negeri Yogyakarta

Direktorat Pembinaan PAUD Kementerian Pendidikan dan Kebudayaan. 2015. Norma, Standar, Prosedur dan Kriteria (NSPK) Petunjuk Teknis Penyelenggaraan Taman Penitipan Anak. Jakarta: Kementerian Pendidikan dan Kebudayaan

Direktorat Pembinaan PAUD Kementerian Pendidikan Nasional. 2011. Petunjuk Teknis Penyelenggaraan Taman Penitipan Anak. Jakarta: Kementerian Pendidikan Nasional

Prihatin, Eka. 2011. Teori administrasi pendidikan. Bandung: Alfabeta.

Slameto. 2009. Manajemen Pendidikan. Salatiga: Widya Sari Press

Sugiyono. 2012. Metode Penelitian Kuantitatif, Kualitatif, dan $R \&$ D. Bandung: Penerbit Alfabeta

Suryosubroto, B. 2004. Pengantar administrasi di sekolah. Yogyakarta: IKIP Yogyakarta.

Susilo, Muhammad Joko. 2008. Kurikulum Tingkat Satuan Pendidikan: Manajemen pelaksanaan dan Kesiapan Sekolah Menyongsongnya. Yogyakarta: Pustaka Pelajar. 